\title{
CHANGES IN CARDIOVASCULAR AND RESPIRATORY SYSTEMS IN YOUNG ATHLETES
}

\author{
Senatorova G., Onikiienko O. \\ Kharkiv National Medical University, Kharkiv, Ukraine \\ https://doi.org/10.35339/ic.7.3.139-145
}

\begin{abstract}
Changes in cardiorespiratory complex of adult athletes are the subject of scientific researches. However, there is a lack of researches that would assess such changes in children and adolescents involved in intensive physical training. The purpose of the study was to evaluate functional and morphological changes of cardiovascular and respiratory systems in boys of primary school age engaged in football. Materials and methods. 109 male children aged 10-11 years were enrolled in the study, among which 81 children have been attending sports football schools, 28 children didn't have regular physical activity. The study design included a general clinical examination, a spirometry, the condition of cardiovascular system was assessed with echocardiography, exercise stress test with cycle ergometer (VEM), and ambulatory blood pressure monitoring (ABPM). Results. The boys 10-11 years of age who play sports have higher values of minute respiratory volume and cardiac indices, which may support the hypothesis of the myocardial hypertrophy development, although they correspond to normal Z-score values. The incidence of complaints in boys who do not practice football is significantly higher during the exercise test. According to ABPM results The duration of physical activity may influence on transition from vasodilation to vasoconstriction. Conclusions. We obtained statistically significant quantitative differences in the functional state of the cardiovascular and respiratory systems in children-athletes. The changes found in young athletes may result to further supervision of a pediatric cardiologist, but decision should be made individually.
\end{abstract}

Keywords: cardiovascular system; football; primary school children; respiratory system.

\section{Introduction}

Physical activity is an important determinant of the general health in children [1]. Modern recommendations of such organizations as the American Academy of General Medicine, the American Academy of Pediatrics, the American College of Sports Medicine, the American Medical Society for Sports Medicine, the American Orthopedic Society for Sports Medicine, and the recommendations of the American Heart Association and the European Society of Cardiology (2019) relate to the fact that, first, before a child is involved in sports, he or she must be examined for respiratory and cardiovascular diseases. Nevertheless, it is necessary to remove

Corresponding Author:

Oleksandr Onikiienko, MD, PhD student

of the Pediatrics №1 and Neonatology Department, Kharkiv National Medical University, Kharkiv, Ukraine. E-mail: alo.khnmu@gmail.com unnecessary restrictions on participation in sports or exercise program [2]. Unnecessary restrictions usually apply not due to abnormal condition of respiratory and cardiovascular systems, but rather arise from concerns about complications that could be avoided by preventive measures [3]. The concern is that one of the current problems in all countries of the world is the problem of mortality during sports competitions [4]. Sudden death in young athletes occurs with a frequency of 1 in 50,000 per year [5]. Despite the fact that sudden cardiac death at a young age is quite rare, each of these cases is a tragedy for society and family members, as athletes are considered the healthiest cohort of the population [6]. In 2015, a proposal was issued by the Sport Cardiology Section of the European Association for Cardiovascular Prevention and Rehabilitation "Sudden cardiac arrest in sport - the need for uniform registration", which states that there are large differences in morbidity, registration methods and causes of 
sudden cardiac arrest/sudden cardiac arrest. death in athletes. Such factors of inequality in registration of sudden deaths include age, sex, presence of comorbid disease, geographical region and participation in sports [7]. The sudden cardiac death is often associated with "hidden" cardiorespiratory pathology. Therefore, today it is recommended to develop strategies based on evidence and expert consensus, health policy aimed at protecting young athletes from such dramatic events [8].

The role of airway obstruction in the development of sudden death in athletes is still unclear $[7,8]$.

In recent decades, the pages of medical publications were dedicated to the search for methods for predicting the occurrence of exercise-induced bronchial obstruction in athletes $[9,10]$. It has been shown that the subjective symptoms of exercise-induced bronchial obstruction before and after beta2-agonist administration do not correlate with the changes in airway caliber in athletes. Therefore, subjective assessments of respiratory symptoms after treatment with inhaled beta2-agonists should not be used as the only diagnostic tool to detect this condition [11].

The "gold standard" for determining aerobic fitness for exercise is measurement of respiratory gas exchange, but physiological responses to exercise during the growth and development of children are still poorly understood, especially in children athletes $[2,12]$.

Recent literature reviews suggest that there are difficulties faced by family physicians in diagnosing exercise-induced respiratory disorders. These difficulties arise not only due to lack of awareness in this matter, but also due to lack of access to special tests for their diagnosis [13, 14]. However, it is not yet clear how family physicians diagnose exercise-induced bronchial obstruction. Moreover, the diagnosis of bronchial obstruction caused by exercise in adult athletes is difficult, and in children it may not be defined at all $[15,16]$.

\section{Purpose, subjects and methods:}

2.1. The purpose of the research is to define morphological and functional changes of the cardiorespiratory complex in boys of primary school age engaged in football.

\subsection{Subjects \& Methods}

109 boys at the age of 10-11 years were enrolled in study, of them 81 children attended sports football schools, 28 children did not have regular physical activity. The children were divided into groups according to duration of football school attendance: group 1 - children who were engaged in football for more than 4 years, $\mathrm{n}=26$; Group 2 consisted of the children engaged in football from 2 to 4 years, $n=34$; Group 3 included the children who played football for less than 2 years, $n=21$. The control group (group 4 ) consisted of clinical data from 28 boys of the same age, who do not play sports and have no health problems. Inclusion criteria were: $10-11$ year old boys involved in football. Exclusion criteria were: female children, age less than 10 years or 12 and more years, history of confirmed genetic pathology, and any acute condition within 3 months prior to recruiting.

The study design included a general clinical examination, spirometry (PFT), condition of cardiovascular system assessed with echocardiography, exercise stress test with cycle ergometer (VEM), and ambulatory blood pressure monitoring (ABPM).

PFT studies were performed using the method of computerized pneumotachography on the devices "Custo-Vit" (Germany) and SpiroCom ("XAI-Medica", Ukraine).

Echocardiography was performed on the devices "Toshiba-Nemio" (Japan) and "Radmir Ultima PA" (Ukraine).

ABPM was performed with "CardioSens ECG+BP" (XAI-MEDICA, Ukraine).

Statistical analysis of the data was performed using statistical packages "Excel for Mac" and "Statistica 7.0. for Windows". Verification of electoral groups for compliance with the Gauss law was performed using Shapiro-Wilk test, which proved the need for nonparametric methods. The median (Me), lower (Lq) and upper (Uq) quartiles of distribution were determined. To compare the characteristics of incidence we used the method of angular transformation with the evaluation of the F-criterion. Non-parametric analysis of variance Kruskal-Wallis ANOVA [KW] was used to compare samples of more than two. Nonparametric Mann-Whitney criterion [MW] was used to compare two independent samples. The difference in parameters was considered statistically significant at $\mathrm{p}<0.05$.

\section{Conflict of interests}

The authors of the article declare no conflict of interest.

\section{Results \& Discussion}

The demographic characteristics of children in all groups as well as early neonatal and general history did not reveal any significant difference. There were no family reported cases of sudden cardiac death. 
Not all of PFT results were acceptable according to ATS/ERS guidelines [17]. Therefore, we excluded from statistical analysis 25 PFTs due to poor start effort or absence of expiratory plateau. The main results of PFT testing are listed in table 1 . greatest values of TV and MVL, however in this group there was a subset of children with decrease in FEV1 that probably would require further PFT monitoring.

Doppler echocardiography did not reveal any

PFT results in boys aged 10-11 years depending on duration

Table 1 of physical activity (Me; (Lq;Uq))

\begin{tabular}{|c|c|c|c|c|c|}
\hline \multirow[b]{2}{*}{ Parameter, units } & \multicolumn{4}{|c|}{ Groups of observation } & \multirow[b]{2}{*}{$\begin{array}{c}\mathrm{p} \\
(\mathrm{KW})\end{array}$} \\
\hline & $\begin{array}{c}\text { Group } 1 \\
n=24\end{array}$ & $\begin{array}{c}\text { Group } 2 \\
n=20\end{array}$ & $\begin{array}{c}\text { Group } 3 \\
n=20\end{array}$ & $\begin{array}{c}4 \text { група } \\
n=20\end{array}$ & \\
\hline VC, I & $\begin{array}{c}2.61 \\
(2.49 ; 2.92)\end{array}$ & $\begin{array}{c}2,78 \\
(2,26 ; 2,91)\end{array}$ & $\begin{array}{c}2,58 \\
(2,32 ; 2,88)\end{array}$ & $\begin{array}{c}2,68 \\
(1,86 ; 2,82)\end{array}$ & 0,5711 \\
\hline FVC, I & $\begin{array}{c}2.95 \\
(2.65 ; 3.25)\end{array}$ & $\begin{array}{c}3,09 \\
(2,82 ; 3,32)\end{array}$ & $\begin{array}{c}3,26 \\
(2,95 ; 3,41)\end{array}$ & $\begin{array}{c}2,95 \\
(2,77 ; 3,05)\end{array}$ & 0,2541 \\
\hline MVL, I/min & $\begin{array}{c}91.5 \\
(55.25 ; 106)\end{array}$ & $\begin{array}{c}95 \\
(86 ; 115,5)\end{array}$ & $\begin{array}{c}88,5 \\
(84,5 ; 106)\end{array}$ & $\begin{array}{c}93 \\
(84 ; 107,5)\end{array}$ & 0,6364 \\
\hline $\begin{array}{l}\% \text { FEV1 of predicted } \\
\text { value, }\end{array}$ & $\begin{array}{c}106.0 \\
(99.0 ; 109.0)\end{array}$ & $\begin{array}{c}108.0 \\
(95.5 ; 117.5)\end{array}$ & $\begin{array}{c}109.0 \\
(97.5 ; 114.0)\end{array}$ & $\begin{array}{c}97.5 \\
(90.5 ; 103.5) \\
\end{array}$ & 0.4066 \\
\hline$\%$ TV & $\begin{array}{c}119,0 \\
(95.0 ; 126.0)\end{array}$ & $\begin{array}{c}103.0 \\
(86.5 ; 118.5)\end{array}$ & $\begin{array}{c}102.0 \\
(97.5 ; 130.0)\end{array}$ & $\begin{array}{c}94.0 \\
(81.5 ; 100.5)\end{array}$ & 0.0555 \\
\hline \multicolumn{6}{|c|}{ MW $\left(p_{1,2}=0.4611 ; p_{1,3}=0.9483 ; p_{1,4}=0.0150 ; p_{2,3}=0.5961 ; p_{2,4}=0.1100 ; p_{3,4}=0.0457\right)$} \\
\hline$\%$ MVL & $\begin{array}{r}135.5 \\
(127.5 \\
157.5)\end{array}$ & $\begin{array}{c}136.0 \\
(125 ; \\
174.5)\end{array}$ & $\begin{array}{c}116.0 \\
(109.75 \\
166.75)\end{array}$ & $\begin{array}{c}112.0 \\
(101.0 ; \\
120.5)\end{array}$ & 0.0243 \\
\hline
\end{tabular}

VC - vital capacity, FVC - forced vital capacity, MVL - minute lung ventilation volume, FEV1 - forced expiratory volume for 1 second, TV - tidal volume; KW - Kruskal-Wallis ANOVA test; MW - Mann-Whitney test.

The changes of the respiratory system, according to PFT results, in boys 10-11 years old who play football, depended on the duration of sports: boys 10-11 years old have an increase in TV and MVL and compared to boys of the same age who did not play sports, even if they were engaged for a short time - up to two years. In the boys 10-11 years who were involved in football for more than 4 years, there were the structural abnormalities in the subjects enrolled in the study. However, there were significantly different values of linear characteristics and left ventricular mass indexed to body surface area (table 2).

All parameters were within normal values according to z-score. According to multifactorial nonparametric analysis, we discovered that in 10 11 years old boys of different sport activity

Table 2

Echocardiographic characterstics in boys aged 10-11 years depending on duration of physical activity (Me; (Lq;Uq))

\begin{tabular}{|c|c|c|c|c|c|}
\hline \multirow[b]{2}{*}{ Parameter, units } & \multicolumn{4}{|c|}{ Groups of observation } & \multirow[b]{2}{*}{$\begin{array}{c}\mathrm{KW} \\
\mathrm{p}\end{array}$} \\
\hline & $\begin{array}{c}\text { Group } 1 \\
n=26\end{array}$ & $\begin{array}{c}\text { Group } 2 \\
n=34\end{array}$ & $\begin{array}{c}\text { Group } 3 \\
n=21\end{array}$ & $\begin{array}{c}\text { Group } 4 \\
n=28\end{array}$ & \\
\hline IVSd, mm & $\begin{array}{c}7.6 \\
(7.3 ; 8.3)\end{array}$ & $\begin{array}{c}7.85 \\
(7.1 ; 8.3)\end{array}$ & $\begin{array}{c}7.9 \\
(7.5 ; 8.1)\end{array}$ & $\begin{array}{c}7.9 \\
(7.5 ; 8.1)\end{array}$ & 0.0018 \\
\hline \multicolumn{6}{|c|}{ MW: $p_{1,2}=0.9586 ; p_{1,3}=0.5886 ; p_{1,4}=0.0038 ; p_{2,3}=0.8033 ; p_{2,4}=0.0033 ; p_{3,4}=0.8847$} \\
\hline LVPWd, mm & $\begin{array}{c}7.8 \\
(7 . ; 8.5)\end{array}$ & $\begin{array}{c}7.75 \\
(6.9 ; 8.3)\end{array}$ & $\begin{array}{c}7.9 \\
(7.6 ; 8.1)\end{array}$ & $\begin{array}{c}6.9 \\
(6.3 ; 7.4)\end{array}$ & 0.0029 \\
\hline \multicolumn{6}{|c|}{ MW: $p_{1,2}=0.7502 p_{1,3}=0.6182 ; p_{1,4}=0.0036 ; p_{2,3}=0.5303 ; p_{2,4}=0.0087 ; p_{3,4}=0.0956$} \\
\hline LVMMi, $\Gamma / M^{2}$ & $\begin{array}{c}81.05 \\
(70.05 ; 86.97)\end{array}$ & $\begin{array}{c}77.75 \\
(71.84 \\
93.44) \\
\end{array}$ & $\begin{array}{c}82.15 \\
(72.64 ; \\
90.01) \\
\end{array}$ & $\begin{array}{r}64.17 \\
(53.86 \\
68.90) \\
\end{array}$ & 0.0001 \\
\hline \multicolumn{6}{|c|}{$M W: p_{1,2}=0.7841 ; p_{1,3}=0.8239 ; p_{1,4}=0.0011 ; p_{2,3}=0.7637 ; p_{2,4}=0.0001 ; p_{3,4}=0.0487$} \\
\hline RVDd, mm & $\begin{array}{l}17.65 \\
(16.8 ; \\
18.50)\end{array}$ & $\begin{array}{c}16.80 \\
(16.20 ; 17.20)\end{array}$ & $\begin{array}{l}16.55 \\
(15.95 ; \\
18.15)\end{array}$ & $\begin{array}{l}16.30 \\
(16.11 ; \\
17.00)\end{array}$ & 0.0193 \\
\hline
\end{tabular}

IVSd - Interventricular septum thickness at end-diastole, LVPWd- left ventricular posterior wall at end-diastole, LVMMi - left ventricle mass index, RVDd- right ventricular dimension at end-diastole; KW - Kruskal-Wallis ANOVA test ; MW - Mann-Whitney test. 
duration there were indices of heart morphology that reflects development of myocardial hypertrophy. LVMMi was significantly higher in all boys involved in sport comparing to the group of control. Left ventricular posterior wall was bigger in those who have been training for more than 2 years. And the right ventricular dimension was increased in boys who played football over 4 years without significant difference in other groups.

ABPM evaluations did not reveal any significant difference of elevated blood pressure. But in the beginning of training (children of group 3), the lowest values of DBP occur during the day $(\mathrm{p}=0.0495)$ (figure).

Nocturnal changes in BP by non-dipper type $(<10 \%)$ were registered in $8(13.1 \%)$ children differences in functional respiratory parameters in athletes in different sports by measuring lung volume and the influence of the factors that most affect respiratory function. But this study, in contrast to ours, included men aged $18-35$ years. The authors concluded that although all anthropometric characteristics differed significantly between groups, they correlated with respiratory parameters and participation in sports is associated with respiratory adaptation, and the degree of adaptation depends on the type of activity. Endurance sports athletes have higher lung volumes in comparison with skill, mixed and power group of sport [103].

Our study of 10-11 year old boys who were playing football showed an increase in LVPWd,

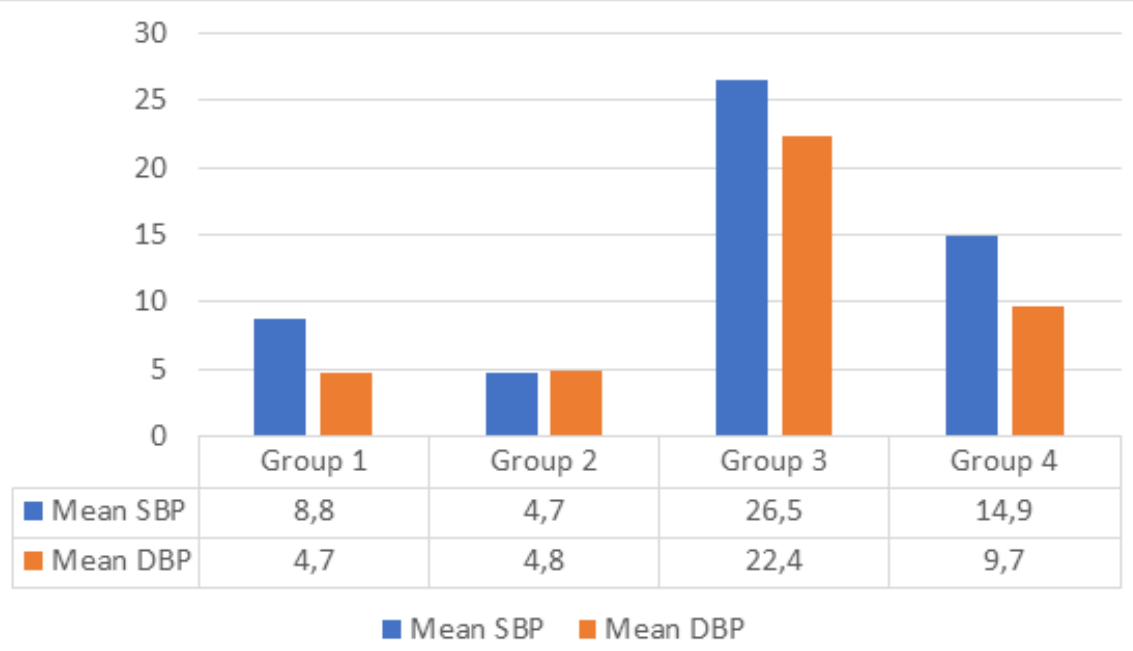

The prevalence of decreased systolic blood pressure (SBP) and diastolic blood pressure (DBP) during daytime in boys aged 10-11 years depending on the physical activity duration (\%)

engaged in sports and not registered in children not engaged in sports $(\mathrm{p}=0.1088)$; by type of over-dipper $(>20 \%)$ was registered in $9(14.7 \%)$ children engaged in sports and in $2(9.0 \%)$ children not engaged in sports $(\mathrm{p}=0.4810)$, night peak is very low blood pressure index was registered in $1(5 \%)$ child with sports experience over 4 years.

\section{Discussion}

The results of the relationship between anthropometric data and PFT values in child populations of many, even low-income countries have already been published [98-102]. However, there is no such data in Ukraine.

PFT values recommended as normal by the American Thoracic Society/European Respiratory Society (ATS/ERS) for the general population, cannot be used in the athlete population [17]. Although it is well known that exercise can affect the lung volume, the effect of sports activity on lung function testing has never been studied [23]. In 2016, a study was published that examined
IVSd, LVMMi and RV dimension caused by sports training duration, but these increases did not go beyond the upper limits of the centile distribution for age, height and body weight. Therefore, we cannot imply on the development of an athletic heart syndrome. But the number of works covering the study of the formation of the athletic heart in childhood, depending on the sport, remains small.

There is little information on the adaptation of the right ventricle to exercise in children. One study looked at the effect of 5 months of intensive training on the morphology and function of the right ventricle in 94 swimmers aged $10.8 \pm 0.2$ years. The researchers showed that after 5 months of intensive training, the end-diastolic dimension of the right ventricle increased $(24.9 \pm 4.1$ vs $23.6 \pm$ $3.0 \mathrm{~mm} / \mathrm{m}^{2}, \mathrm{p}=0.15$ ) at its normal function. The authors considered this not as a manifestation of cardiomyopathy, but a normal reaction to exercise. We obtained similar data [24]. 
The hypothesis of cardiac muscle remodeling was tested in a study of the adaptation of the left and right atria in 5-month training of 94 children (57 athletes and 37 sedentary children) aged $10.8 \pm$ 0.2 and $10.2 \pm 0.2$ years. The size of these heart chambers and their contractile capacity in athletes are increased, which suggests that morphological adaptation occurs in the early stages of sports careers in children, which is similar to the results of our study [25].

Another recent study of children similar to ours enrolled skiers aged $12.1 \pm 0.2$ years, showed morphological and functional changes in the heart. In young athletes comparing with those who do not do sports, increased end-diastolic volume $(79 \pm$ 7 vs. $\left.68 \pm 7 \mathrm{ml} / \mathrm{m}^{2}, \mathrm{p}<0.001\right)$, LVMMi $(69 \pm 12$ vs. $\left.57 \pm 13 \mathrm{~g} / \mathrm{m}^{2}, \mathrm{p}<0.001\right)$, diameter of the right ventricle $\left(28.3 \pm 3.0\right.$ vs. $\left.25.4 \pm 3.5 \mathrm{~mm} / \mathrm{m}^{2}, \mathrm{p}<0.001\right)$ and diameter of the right atrium (10.6 $\pm 1.4 \mathrm{vs.}$ $9.7 \pm 1.2 \mathrm{~cm}, \mathrm{p}<0.01)$. There was no difference in left ventricle ejection fraction [26].

Another problem of medicine, which was subject of our study, but that remain unsolved is the adaptation of blood vessels to exercise and hypertension in athletes [27]. Static and dynamic components of physical activity (overload), i.e. cardiovascular stress, vary depending on the needs of a particular sport or activity. As an example, a football midfielder who runs to the goal is engaged in dynamic exercises. Systolic blood pressure rises during endurance and dynamic exercise; both systolic and diastolic blood pressure increase during resistance or static exercise. These increases in blood pressure reflect the body's efforts to increase cardiac output to meet the metabolic needs of working muscles [27]. The epidemiological prevalence of the hypertension in athletes has not been established.

In a study of 3697 athletes (men and women aged 19 to 49 years), the authors noted that the value of blood pressure in athletes who played sports "dynamic type" (speed, endurance, ball games) is higher than in sports "static type". It was noted that water sports athletes have a higher blood pressure [27].

According to a retrospective cohort study of male athletes from 636 football teams, it was concluded that the prevalence of hypertension among football players is higher than among nonfootball players [29]. There is no known increased risk of developing hypertension in weightlifters or other strong athletes (eg, discus throwers, shooters) [30].

The limitation of our study is a small sample of boys 10-11 years of age who are engaged in football and lack of information of their history of trainings.

\section{Conclusions}

The boys 10-11 age who are engaged in football do not present with significant decrease in PFT that may be considered as bronchoconstriction. The duration of athletic activity affects minute respiratory volume. We obtained statistically significant quantitative differences in the heart morphology and mean blood pressure. The identified changes should be estimated with personalized approach in each case and should not be considered as criteria for sport discontinuation.

\section{References}

1. State of play 2018; Sports participation rates in children ages 6 to 12 years in the United States. Available at: https://www.aspenprojectplay.org/kids-sports-participation-rates (Accessed on January 06, 2020).

2. American Academy of Pediatrics, American Academy of Family Physicians, Am College of Sports Med. Preparticipation Physical Evaluation, $5^{\text {th }}$ Ed, American Academy of Pediatrics, Elk Grove Village, IL 2019.

3. Maron BJ, Levine BD, Washington RL, et al. Eligibility and Disqualification Recommendations for Competitive Athletes with Cardiovascular Abnormalities: Task Force 2: Preparticipation Screening for Cardiovascular Disease in Competitive Athletes: A Scientific Statement from the American Heart Association and American College of Cardiology. Circulation 2015; 132:e267.

4. Feng XF, Hai JJ, Ma Y, Wang ZQ, Tse HF. Sudden Cardiac Death in Mainland China. Circ Arrhythm Electrophysiol. 2018 Nov;11(11):e006684. doi: 0.1161/CIRCEP.118.006684.

5. Asif IM, Harmon KG. Incidence and Etiology of Sudden Cardiac Death: New Updates for Athletic Departments. Sports Health. 2017; 9(3):268-79. doi: 10.1177/1941738117694153.

6. Michael W. Luong, Barbara N. Morrison, Daniel J. Lithwick, Saul Isserow, Brett Heilbron, Andrew D. Krahn, MD. Sudden cardiac death in young competitive athletes. BCMJ 2016: 58 (3): 138-44.

7. Solberg EE, Borjesson M, Sharma S, Papadakis M, Wilhelm M, Drezner JA, Harmon KG, Alonso JM, Heidbuchel H, Dugmore D, Panhuyzen-Goedkoop NM, Mellwig KP, Carre F, Rasmusen H, Niebauer 
J, Behr ER, Thiene G, Sheppard MN, Basso C, Corrado D; Sport Cardiology Section of the EACPR of the ESC. Sudden cardiac arrest in sports - need for uniform registration: A Position Paper from the Sport Cardiology Section of the European Association for Cardiovascular Prevention and Rehabilitation. Eur J Prev Cardiol. 2016 ;23(6):657-67. doi: 10.1177/2047487315599891.

8. Michael Ackerman, Dianne L Atkins, and John K Triedman. Sudden cardiac death in the young: Circulation. 2016 Mar 8; 133(10): 1006-1026. doi: 10.1161/CIRCULATIONAHA.115.020254

9. James H. Hull, Les Ansley, Oliver J. Price, John W. Dickinson, Matteo Bonini. Eucapnic Voluntary Hyperpnea: Gold Standard for Diagnosing Exercise-Induced Bronchoconstriction in Athletes? Sports Med. 2016; 46: 1083-1093. doi:10.1007/s40279-016-0491-3

10.Jean MM Driessen, Margryt Gerritsma, Jaap Westbroek, Nick HT ten Hacken, Frans HC. The effect of nebulized salbutamol or isotonic saline on exercise-induced bronchoconstriction in elite skaters following a 1,500-meter race: study protocol for a randomized controlled trial. de Jongh Trials. 2013; 14: 204. doi: $10.1186 / 1745-6215-14-204$

11. Andrew j. Simpson, Lee M. Romer, and Pascale Kippelen. Self-reported Symptoms after Induced and Inhibited Bronchoconstriction in Athletes Med Sci Sports Exerc. 2015 Oct; 47(10): 2005-2013. doi: 10.1249/MSS.0000000000000646

12. Takken T, Bongers BC, van Brussel M, Haapala EA, Hulzebos EHJ. Cardiopulmonary Exercise Testing in Pediatrics. Ann Am Thorac Soc. 2017;14 (1): 123-8. doi: 10.1513/AnnalsATS.201611-912FR.

13. Schwartz LB, Delgado L, Craig T, Bonini S, Carlsen KH, Casale TB, Del GS, Drobnic F, van Wijk RG, Ferrer M, et al. Exercise-induced hypersensitivity syndromes in recreational and competitive athletes: a PRACTALL consensus report (what the general practitioner should know about sports and allergy) Allergy. 2008; 63:953-961. doi: 10.1111/j.1398-9995.2008.01802.x.

14.James H Hull, Peter J Hull, Jonathan P Parsons, John W Dickinson, and Les Ansley. Approach to the diagnosis and management of suspected exercise-induced bronchoconstriction by primary care physicians. BMC Pulm Med. 2009; 9: 29. doi: 10.1186/1471-2466-9-29

15.Campbell RM, Berger S. Preventing pediatric sudden cardiac death: where do we start? Pediatrics 2006; 118:802.

16. Carek PJ, Mainous AG 3rd. A thorough yet efficient exam identifies most problems in school athletes. J Fam Pract. 2003; 52:127.

17. Brian L. Graham, Irene Steenbruggen, Martin R. Miller, Igor Z. Barjaktarevic, Brendan G. Cooper, Graham L. Hall,..., Bruce R. Thompson (2019) Standardization of Spirometry 2019 Update An Official American Thoracic Society and European Respiratory SocietyTechnical Statement. Am J Respir Crit Care Med Vol 200, Iss 8, pp e70-e88, Oct 15, 2019

18. Bajo JM, Mangeaud A. Relationship between the lung function and anthropometric measures and indexes in adolescents from Cordoba, Argentina. Am J Hum Biol. 2010;22(6):823.

19. Alexandraki S, Koutsilieris M, Siafakas N, Katsardis C. Spirometric reference values in greek children and adolescents. In Vivo. 2010 Mar-Apr; 24(2):195-200.

20. Martinez-Briseno D, Fernandez-Plata R, Gochicoa-Rangel L, Torre-Bouscoulet L, Rojas-Martinez R, Mendoza-Alvarado L, Garcia-Sancho C, Perez-Padilla R. Socioeconomic Status and Longitudinal Lung Function of Healthy Mexican Children. PLoS One. 2015 Sep 17;10(9):e0136935. doi: 10.1371/ journal.pone.0136935.

21.Kuti BP, Oladimeji OI, Kuti DK, Adeniyi AT, Adeniji EO, Osundare YJ. Rural-urban disparity in lung function parameters of Nigerian children: effects of socio-economic, nutritional and housing factors. Pan Afr Med J. 2017 Nov 15;28:230. doi: 10.11604/pamj.2017.28.230.13836.

22.Evans EW, Koinis-Mitchell D, Kopel SJ, Jelalian E. Lung Function, Dietary Intake, and Weight Status in Children with Persistent Asthma from Low-Income, Urban Communities. Nutrients. 2019 Dec 3; 11(12). pii: E2943. doi: 10.3390/nu11122943.

23.Lazovic B, Mazic S, Suzic-Lazic J, Djelic M, Djordjevic-Saranovic S, Durmic T, Zikic D, Zugic V. Respiratory adaptations in different types of sport. Eur Rev Med Pharmacol Sci. 2015;19(12):2269-74.

24.D'Ascenzi F, Pelliccia A, Valentini F, Malandrino A, Natali BM, Barbati R, Focardi M, Bonifazi M, Mondillo S.Training-induced right ventricular remodelling in pre-adolescent endurance athletes: The athlete's heart in children. Int J Cardiol. 2017 Jun 1;236:270-275. doi: 10.1016/j.ijcard.2017.01.121.

25.D'Ascenzi F, Solari M, Anselmi F, Maffei S, Focardi M, Bonifazi M, Mondillo S, Henein M. Atrial chamber remodelling in healthy pre-adolescent athletes engaged in endurance sports: A study with a 
longitudinal design. The CHILD study. Int J Cardiol. 2016 Nov 15;223:325-330. doi: 10.1016/ j.ijcard.2016.08.231. Epub 2016 Aug 14.

26. Bjerring AW, Landgraff HE, Leirstein S, Aaeng A, Ansari HZ, Saberniak J, Murbrech K, Bruun H, Stokke TM, Haugaa KH, Hall?n J, Edvardsen T, Sarvari SI. Morphological changes and myocardial function assessed by traditional and novel echocardiographic methods in preadolescent athlete's heart. Eur J Prev Cardiol. 2018 Jun;25(9):1000-1007. doi: 10.1177/2047487318776079. Epub 2018 May 22.

27.Black HR, Sica D, Ferdinand K, et al. Eligibility and Disqualification Recommendations for Competitive Athletes With Cardiovascular Abnormalities: Task Force 6: Hypertension: A Scientific Statement from the American Heart Association and the American College of Cardiology. Circulation 2015; 132:e298.

28. Varga-Pinter B, Horvath P, Kneffel Z, et al. Resting blood pressure values of adult athletes. Kidney Blood Press Res 2011; 34:387.

29. Karpinos AR, Roumie CL, Nian H, et al. High prevalence of hypertension among collegiate football athletes. Circ Cardiovasc Qual Outcomes 2013; 6:716.

30. Sharman JE, LaGerche A. Exercise blood pressure: clinical relevance and correct measurement. J Hum Hypertens 2015; 29:351.

Received: 04-Jun-2020

Accepted: 11-Sep-2020 